\title{
DETERMINATION OF REFRACTION AND PROGRESS OF FUNDAMENTAL ASTROMETRY
}

\author{
A.Yu. YATSENKO \\ Engelhardt Astronomical Observatory \\ $422526 \mathrm{Kazan}$ \\ USSR
}

\section{Introduction}

The potentional possibility of high precise instruments of fundamental astrometry cannot be realized because we have a bad refraction determination: the instrumental accuracy of these telescopes is about 0:01 (Yoshizawa 1987) and the real accuracy of determination of declinations is 0.20 . The theoretical possibility of determining real refraction with a precision of 0.01 to 0.05 is shown. According to Kolchinskij (1987) astronomical refraction can be divided into the following components:

Table 1. Refraction fluctuations

\begin{tabular}{llll}
\hline $\mathrm{N}$ & $\begin{array}{l}\text { Types } \\
\text { High frequency (image } \\
\text { motion) }\end{array}$ & $\begin{array}{l}\text { Quasi-period, sec } \\
0.001-1\end{array}$ & $\begin{array}{l}\text { Notes } \\
\text { r.m.s. deviation computed by special formulas }\end{array}$ \\
2 & $\begin{array}{l}\text { Medium frequency } \\
\text { (accidental refraction) }\end{array}$ & $1-1000$ & $\begin{array}{l}\text { Gravitational waves. Not computed by the } \\
\text { theory of refraction. }\end{array}$ \\
3 & $\begin{array}{l}\text { Low frequency } \\
\text { diurnal variation, annual }\end{array}$ & $1000-10000000$ & $\begin{array}{l}\text { Computed by the theory of refraction or tables } \\
\text { (normal refraction) } \\
\text { Not computed by the theories of refraction }\end{array}$ \\
4 & - Low frequency & - & (anomalies)
\end{tabular}

The first type of fluctuations can be reduced with the impersonal photoelectric micrometer if it has about 100 registrations of star positions during an observation. Computations by Yatsenko (1989) show that this refraction type can be reduced to about 0 " 03 during one observation with probability 0.90. A part of the second type is reduced in this manner also. The remainder of the second type and the fourth type of the fluctuations are computed by using aerological and meteorological information in order to do its correct calculation.

\section{Determination of accidental refraction and anomalies of refraction}

Let's divide the atmosphere into two refraction parts:

1. Surface Layer is up to the altitude at which the influences of buildings and relief peculiarities to the horizontal temperature gradients disappear. Depending on locality it is from 
0.02 to $0.1 \mathrm{~km}$.

2. Free Atmosphere is from 0.1 to $82 \mathrm{~km}$.

\subsection{THE INFLUENCE OF THE FREE ATMOSPHERE}

For the accurate determination of this influence one should obtain the answers to the following questions: (1) What is the tolerable absolute error of aerological probe sensors? (2) Does it correspond to the real error of these devices? (3) Is the number of levels in the current aerological practice enough? (4) What is the greatest tolerable distance of an aerological station from an observation place?

For obtaining answers to these questions Yatsenko $(1987,1988,1989)$ has fulfilled particular computations by the using spatial (three-dimensional) theory of refraction. The results have shown the following: (1) The error of $0.8^{\circ} \mathrm{K}$ leads to the error of a refraction computation equal or less than 0.004 . (2) It corresponds to the real error of aerological devices. (3) The number of levels in the current aerological practice is enough for evaluating the refraction in the free atmosphere with accuracy better than $0: 01$. (4) A distance to $400 \mathrm{~km}$ between the aerological station and observing site allows one to evaluate the refraction with error less than 0.01 .

For observations at zenith distances $0-60^{\circ}$ a spatial area which propagates a light ray, is a cylinder with radius $140 \mathrm{~km}$ and altitude $82 \mathrm{~km}$. But $98 \%$ of the refraction effect appears in a smaller area: a cylinder with radius $46 \mathrm{~km}$ and altitude $27 \mathrm{~km}$. Thus aerological probes actually provide us with information about the whole second refraction part of the atmosphere and with sufficient accuracy.

\subsection{THE INFLUENCE OF THE SURFACE LAYER}

An altitude of a surface layer for every place on the Earth is particular. Evidently, anomalies of the refraction in surface layer is the main cause of the whole refraction anomalies. For its determination one needs a spatial set of meteorological sensors. A system for the collection of meteorological data should consist of 6 masts or fasted balloons with height $0.02-0.1 \mathrm{~km}$ equipped mainly with temperature sensors. The masts should be disposed in N-S direction by pairs: the one in the plane of the first vertical and two others at a distance $170 \mathrm{~m}$ from an instrument.

The accuracy of three sensors above the system should be $0.02{ }^{\circ} \mathrm{K}$ (for evaluating the main part of astronomical refraction), the others from $0.8^{\circ} \mathrm{K}$ (at the top) to $0.02^{\circ} \mathrm{K}$ in a vicinity of an instrument (for obtaining of the tilts of the equal refractive index surfaces which can be vertical (Yatsenko 1985).

The processing of the whole information should carry out with the "cube"-method (Yatsenko 1985) by using spatial theory of refraction.

\section{References}

1. Kolchinskij, I.G. (1987) “On terminology in the theory of atmospheric refraction”, Publ. Observ. Astron. Beograd 35, 332-337.

2. Yatsenko, A.Yu. (1985) "On the room refraction", Bull. Observ. Astron. Beograd, 135, 16-20.

3. Yatsenko, A.Yu. (1988) "Refraktsiya w meridional'noj modely atmosfery Teoreticheskiye osnowy", Kinematika i fizika nebesnikh tel 4, 2, 59-66. (In Russian)

4. Yatsenko, A.Yu. (1989a) "Refraktsiya w meridional'nojmodely atmosfery. Algoritm wychislenij", Kinematika i fizika nebesnikh tel 5, 1, 68-74. (In Russian)

5. Yatsenko, A.Yu. (1989b) "Refraktsionnoye obespecheniye wysokotochnikh meridiannykh nablyudenij", Kinematika i fizika nebesnikh tel 5, 3, 84-89. (In Russian)

6. Yoshizawa, M., Suzuki, S., Fukaya, R. (1987) "Tokyo PMC catalog 85”, Ann. Observ. Astron. Tokyo 21,393-421. 